\title{
Base Excess Measurement
}

National Cancer Institute

\section{Source}

National Cancer Institute. Base Excess Measurement. NCI Thesaurus. Code C119270.

The determination of the amount of the base excess in a biological specimen. 